\title{
Short-term upwelling events modulate fish sound production at a mid-Atlantic Ocean observatory
}

\author{
D. A. Mann ${ }^{1, *}$, T. M. Grothues ${ }^{2}$ \\ ${ }^{1}$ University of South Florida, College of Marine Sciences, 140 7th Avenue South, St. Petersburg, Florida 33701, USA \\ ${ }^{2}$ Rutgers University, Institute of Marine and Coastal Sciences, Marine Field Station, 800 c/o 132 Great Bay Blvd., Tuckerton, \\ New Jersey 08087, USA
}

\begin{abstract}
Understanding factors controlling the distribution and reproduction of fishes is crucial for developing ecosystem models of fish populations. Yet, these observations are difficult to make on the same time and space scales as physical forcing events. A hydrophone was used to record fish sound production associated with reproduction at the LEO-15 ocean observatory to determine the relationship between variation in fish calling behavior and oceanographic variation. Sound production was dominated by Atlantic croaker Micropogonias undulatus, weakfish Cynoscion regalis, and striped cusk-eel Ophidion marginatum. Striped cusk-eels called with a crepuscular pattern, with a strong peak at dusk, less sound production during the night, and a lesser peak in sound production at dawn. Sciaenids called mostly at dusk and night. Nine advection events bringing colder waters to the LEO-15 site were correlated with greatly reduced levels of sound production in Atlantic croaker and weakfish on daily time scales. Our results show how ocean observatories with passive acoustics can study tightly coupled physical oceanographic influences on fish behavior on daily time scales.
\end{abstract}

KEY WORDS: Sciaenid · Cusk-eel · Passive acoustics · Ocean observatory

\section{INTRODUCTION}

Many marine fishes produce sound during courtship and spawning. Passive hydrophone surveys take advantage of this to document the distribution and behavior of soniferous fishes over large spatial and temporal scales (Breder 1968, Mok \& Gilmore 1983, Saucier \& Baltz 1993, Mann \& Lobel 1995, Luczkovich et al. 1999, 2008, Zelick et al. 1999). Passive acoustics research has focused on describing the temporal and spatial patterns of sound production. These studies have found that many fishes produce sounds with a diel pattern (Mann \& Lobel 1995, Locascio \& Mann 2008). However, little effort has been focused on exploring environmental correlates of variability in sound production.

A cabled long-term ecosystem observatory (LEO-15) in southern New Jersey, near the zonal center of the northeastern United States continental shelf (NEUSCS) province has offered the ability to make extended recordings of fish sounds over a wide frequency band in concert with oceanographic data collection. The NEUSCS experiences one of the highest annual temperature variations $\left(-0.5\right.$ to $\left.35.5^{\circ} \mathrm{C}\right)$ of any oceanographic province worldwide. Much of the ichthyofauna responds by migrating along with the seasonal progression of isotherms (Musick et al. 1989), but the details of this response on short and long time scales and its relationship to spawning site choice are not well known. The region is characterized by a broad $(130 \mathrm{~km})$ expanse of sedimentary continental shelf, with relatively low relief and little hard bottom or reef. Therefore, it lacks the well-defined promontories that define spawning habitat for sub-tropical and tropical reef fishes, and spawning habitat remains poorly characterized or unknown for most of the region's species beyond broad-scale maps of egg occurrence. The region's oceanography is highly dynamic, under the influence of episodic mesoscale advective features originating in the sub-tropics (Gulf Stream), sub-boreal (cold pool), local large estuaries (Hudson and Delaware Rivers and 
Chesapeake Bay tributaries), and local wind forcing, including upwelling and hurricanes (Bumpus 1973, Beardsley et al. 1976, Churchill \& Cornillon 1991, Flagg et al. 1994). Several species of soniferous fishes spawn in these coastal waters, including weakfish Cynoscion regalis, spot Leiostomus xanthurus, Atlantic croaker Micropogonias undulatus, black drum Pogonias cromis, striped cusk-eel Ophidion marginatum, and striped and northern searobins Prionouts evolans and P. carolinas (Able \& Hagan 1995, Martino \& Able 2003). Spot and Atlantic croaker are at the northern end of their range off New Jersey, and local spawning and recruitment appear to fluctuate dramatically in response to temperature (Grothues \& Able 2003, Hare \& Able 2007). LEO15 offers the opportunity to collect simultaneous oceanographic data and passive acoustics data to explore environmental correlates of variability in fish sound production.

We deployed a hydrophone at the LEO-15 to explore fish sound patterns on event to long-term time scales. The goals were to determine the timing of soniferous fish sound production at the coastal ocean study site and perform time-series analysis of sound production data and oceanographic data to determine how physical parameters may influence daily and seasonal patterns of sound production. We show that short-term upwelling events, on the order of days, are tightly correlated with variability in fish sound production.

\section{MATERIALS AND METHODS}

Study site and data acquisition. LEO-15 is a submarine electro-optical telecommunications platform with a node (Node B) located at the $20 \mathrm{~m}$ isobath of Beach Haven Ridge, a shoreface sand ridge $9.6 \mathrm{~km}$ off the coast of southern New Jersey, USA (39 27.42' N, $74^{\circ} 14.74^{\prime}$ W) (von Alt \& Grassle 1994). The site has a history that includes study of physical oceanographic processes, such as upwelling (e.g. Glenn et al. 1996), fish assemblage dynamics (e.g. Martino \& Able 2003), and oceanographic effects on juvenile fish recruitment (e.g. Vasslides \& Able 2008). Control and real-time data acquisition from supported instruments is at the Rutgers University Marine Field (RUMFS) in Little Egg Harbor, New Jersey. In addition to several science guest ports, LEO-15 supported a profiling conductivity/temperature/depth and dissolved oxygen sensor (CTD) (SBE-25, Sea-bird Electronics) that sampled at $10 \mathrm{~s}$ intervals. The water column was profiled hourly, but the CTD continued sampling while docked to the node on the bottom.

A hydrophone (HTI $96 \mathrm{~min}$; sensitivity -175 dBV $\mu \mathrm{Pa}^{-1}$ from $2 \mathrm{~Hz}$ to $30 \mathrm{kHz}$ ) was installed at Node B on March 24, 2005. The hydrophone was secured to a sand stake $20 \mathrm{~m}$ from the node at $20 \mathrm{~m}$ depth to minimize the recording of noise from the CTD pump and winch motor. The hydrophone signal was digitized at the shore station using a Tucker-Davis Technologies RP2.1 real-time processor at $24414 \mathrm{~Hz}$ with 24 bit sigma-delta analog-to-digital converters. Data were stored as 32 bit floating point values using custom software (FieldLog) written with Microsoft Visual C++. Data were recorded typically for $10 \mathrm{~s}$ every $1 \mathrm{~min}$, although some data were collected continuously at the end of the deployment prior to the LEO-node being removed for a system upgrade on August 24, 2005.

Data analysis. Acoustic data were analyzed with custom signal processing routines written in MATLAB (Mathworks). These routines calculated the band sound pressure level (BSPL) over different frequency bands using the Fast Fourier Transform (FFT) algorithm for each sound file. A composite spectrogram was constructed by concatenating a series of 1024 point FFTs calculated from each sound file.

Temperature, salinity, dissolved oxygen, and pressure data from the CTD were filtered to retain only those collected below $12 \mathrm{~m}$ to remove data from the upper water column collected during profiling. The maximum nightly BSPL characteristic of sciaenid sounds (200 to $300 \mathrm{~Hz}$ ) from the hydrophone were regressed on physical data (temperature, salinity, and dissolved oxygen) measured at the same time as the peak in sound production using a multiple regression model with forward selection (SAS software) in which regressors are added in the order of maximizing fit. The effect of temperature change from the previous night was also tested as in a single factor Model 1 regression. A combination of temperature and salinity was used to identify the onset of upwelling events that move cold and saline bottom water into the study area in response to wind forcing, which was confirmed from AVHRR satellite imagery and CTD water column data.

\section{RESULTS}

Three species of fish, striped cusk-eel Ophidion marginatum, weakfish Cynoscion regalis, and Atlantic croaker Micropogonias undulatus, were the most common sound producers detected at LEO-15 (Fig. 1). Their calls were identified by comparisons to known sounds recorded from each species (Fish \& Mowbray 1970, Mann et al. 1997). Weakfish and Atlantic croaker are sciaenids, and their sounds are characterized by chorusing, whereby many individuals call at the same time to produce an overall increase in the background sound levels (Fig. 1). Sciaenid calling started in May and was recorded through the end of the hydrophone deployment. Sciaenid calls began at dusk and continued 

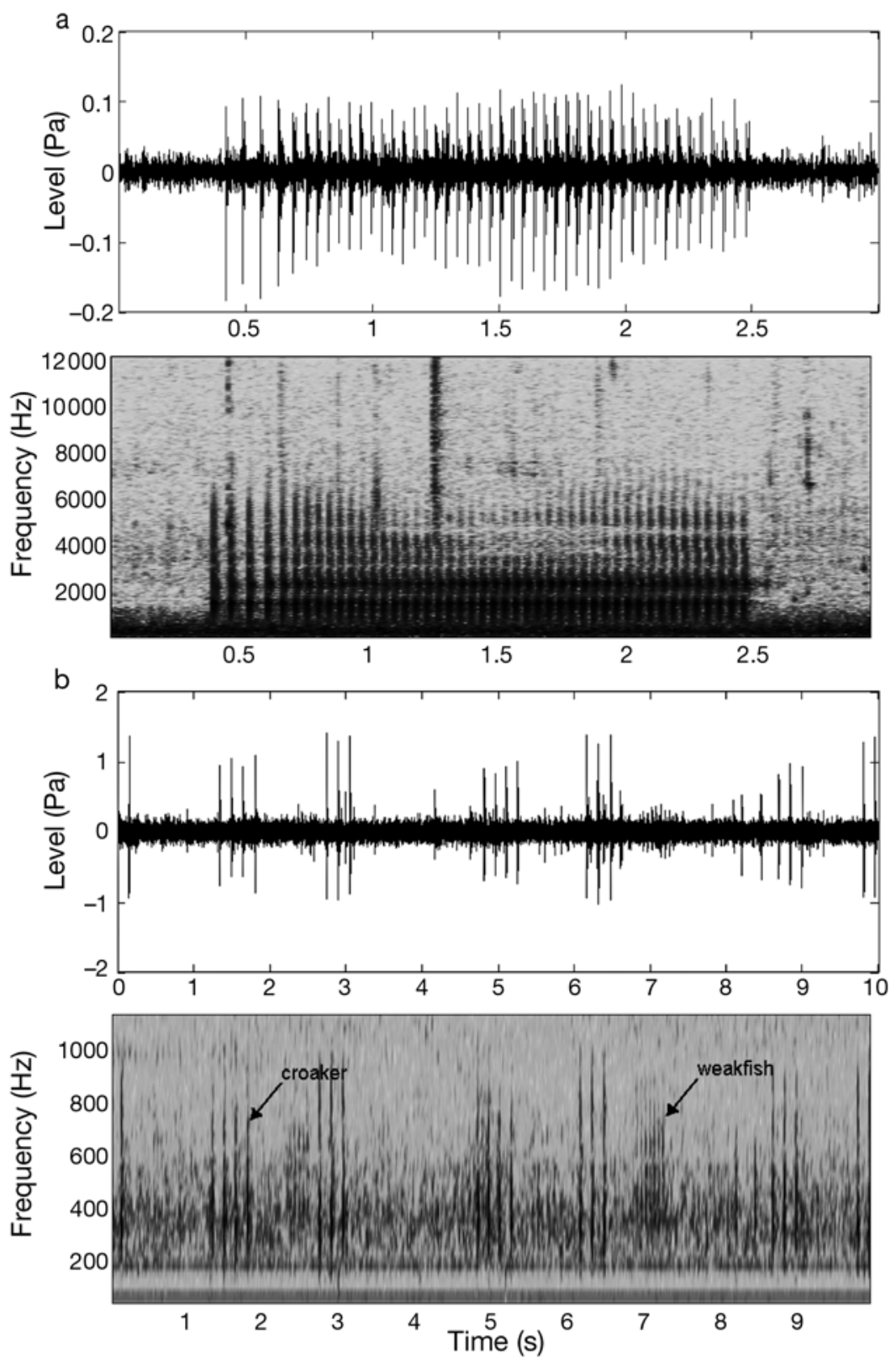

Fig. 1. Ophidion arginatum, Cynoscion regalis, Micropogonias undulatus. (a) Oscillogram (top) and spectrogram (bottom) of cusk-eel sound recorded on LEO-15. The sound consists of repeated pulses with the majority of the energy from 500 to $7000 \mathrm{~Hz}$. (b) Oscillogram (top) and spectrogram (bottom) of $10 \mathrm{~s}$ recording from LEO-15 showing a chorus of weakfish (continuous drone with most energy $<1000 \mathrm{~Hz}$ ) and Atlantic croaker ( 3 to 4 pulse sounds with most of the energy $<500 \mathrm{~Hz}$ ). Spectrogram frequency axis is truncated at $1000 \mathrm{~Hz}$ to expand visibility of low-frequency detail earlier that the sun set, the fish calling was on average $2.7 \mathrm{~min}$ earlier $(\mathrm{r}=$ 0.9892, n $=3 \mathrm{mo}$ ). The striped cusk-eel sounds were recorded first on July 9 and continued until the end of the hydrophone deployment. Striped cusk-eels called with a crepuscular pattern, with a strong peak at dusk, less sound production during the night, and a lesser peak in sound production at dawn (Fig. 2). There were times at night when sciaenid and striped cusk-eel calling overlapped, but there was little overlap in the acoustic frequencies that composed their sounds.

Ocean temperature was the most important explanatory variable in a multiple regression of physical oceanographic variables with the level of nightly maximum sound production between 200 and $300 \mathrm{~Hz}$, which is dominated by sciaenids (Fig. 3, Table 1). Temperature resolved $34 \%$ of the variance (Table 1, Fig. 3). Note that there was little correlation with temperatures $<13^{\circ} \mathrm{C}$ (Fig. 3). For example, sound level could vary by as much as $20 \mathrm{~dB}$ between days that were both $12^{\circ} \mathrm{C}$. The addition of salinity and dissolved oxygen added little explanatory power (3.7 and $2.6 \%$, respectively), and this increased fit was not significant for dissolved oxygen (Table 1). However, variable gradients were not orthogonal; temperature inversely covaried with salinity and episodically with dissolved oxygen (Fig. 4). Between August 20 and 24 , intrusion of cold water produced 7 rapid temperature drops of 3 to $4^{\circ} \mathrm{C}$. The change in temperature from the preceding night was not significant in explaining variability in sound levels. Much of the variability in sound level not explained by temperature was due to variations in sound levels at low temperatures (Fig. 5).

\section{DISCUSSION}

throughout the night, ending by morning (Fig. 2). The time of maximum sound production for sciaenids was 23:24 \pm 01:00 h (SD) in June, 23:06 \pm 00:24 h in July, and 21:48 \pm 01:06 h in August. The time shift in sound production was much greater than the shift in the timing of sunset (June 15: 19:27 EST [eastern standard time]; July 15: 19:24 EST; August 15: 18:53 EST). For every minute
This work documents a correlation of sound production by fishes with temperature and salinity that characterizes both the seasonal onset of reproductive behavior at the study site, as well as short-term responses to episodic features. Responses at both time 


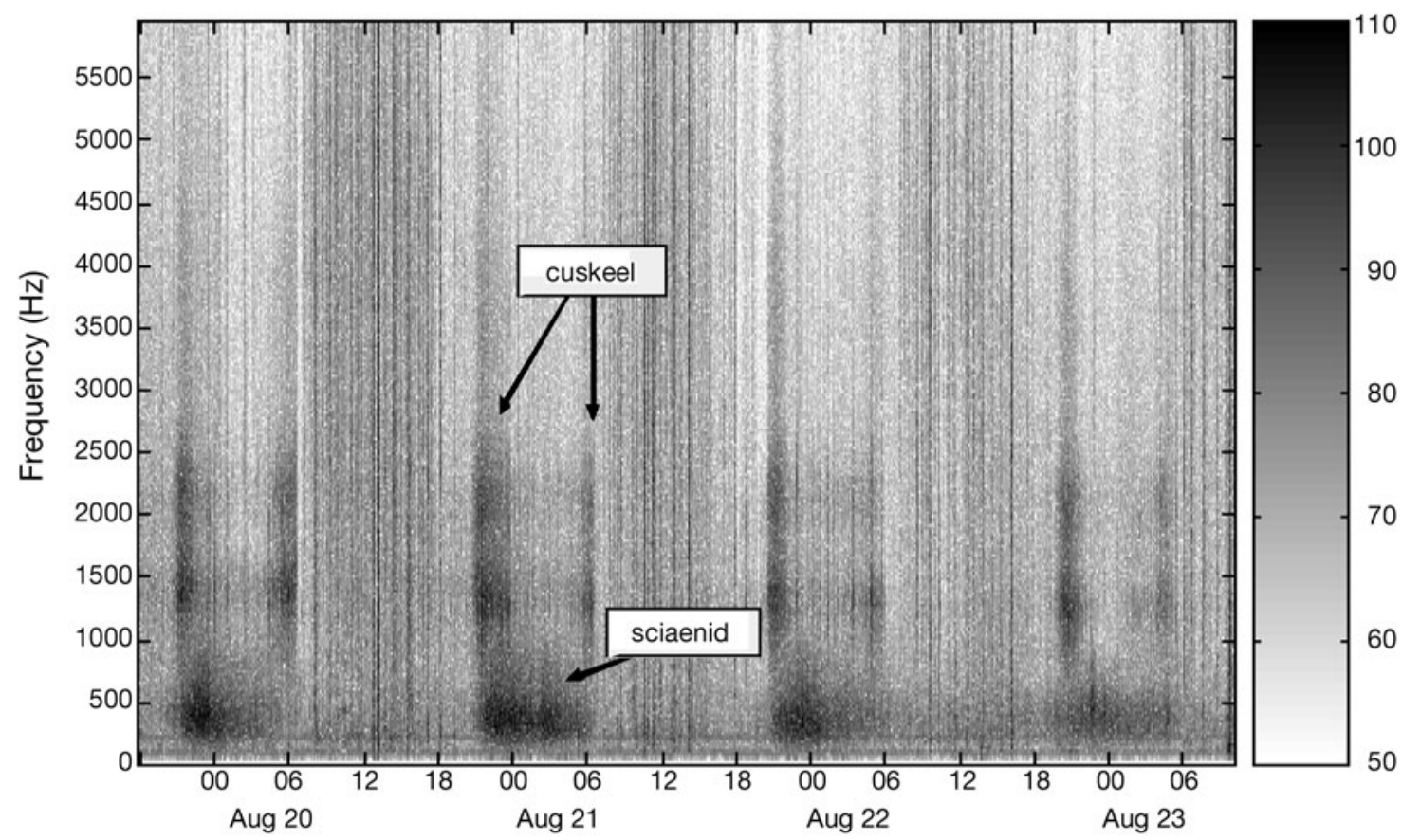

Fig. 2. Ophidion arginatum, Cynoscion regalis, Micropogonias undulatus. Composite spectrogram showing frequency distribution of sound energy from August 20 to 23, 2005 at LEO-15. Sound level is the spectrum level (dB re $1 \mu \mathrm{Pa}^{2} \mathrm{~Hz}^{-1}$ ). Low-frequency sounds between 100 and $600 \mathrm{~Hz}$ from dusk through midnight are from sciaenids (weakfish and Atlantic croaker). High-frequency sounds between 1000 and $2500 \mathrm{~Hz}$ are from crepuscular cusk-eel calling. Cusk-eels have a strong peak in calling at dusk and a small peak in calling at dawn. Arrows indicate sound production by fishes on August 21. Sound production was recorded for both cusk-eels and sciaenids on each day (August 20 to 23)

scales are of interest for understanding and predicting shifting phenologies resulting from long-term ocean climate change. It is not possible from this dataset to determine whether the decreases in sound production associated with upwelling are due to fish movements or due to the fish reducing the number of calls produced. However, it appears from trawl surveys that the fish assemblage can change rapidly with changes in temperature (Vasslides \& Able 2008). This question could be answered by a combination of passive acoustic measurements over a larger spatial scale tagging and tracking fish with transmitters.

Because most fishes are ectothermic, the activity of muscles (including those associated with sound production) is functionally related to ambient water temperature on the short term (Fry 1971, Bryan et al. 1990, McKibben \& Bass 1998). Likewise, seasonal gonadal ripening is linked to temperature cues (Arnold et al. 1976). In the case of striped cusk-eel Ophidion marginatum, a burrowing species not known to migrate, the onset of sound production is probably a case of the latter mechanism as local vernal warming cues spawning. In the case of a migrant such as weakfish Cynoscion regalis, maturation probably begins earlier at overwintering sites near or south of Cape Hatteras, and temperature influences spawning activity locally, either by direct influence of metabolic rate or by attrac- tion to and retention within a suitable spawning area. Interestingly, cusk eels did not reduce their level of calling during the upwelling event, while the level of recorded sounds was reduced for sciaenids.

Lower temperatures usually coincided with higher dissolved oxygen levels during this study period, a relationship that may be reversed during coastal upwelling in the summer (Glenn et al. 2004). During upwelling, southwesterly long-shore winds force warm, low-salinity surface water seaward away from the site via Eckman transport. Near the shore, where land or high-relief sand ridges block replacement by other adjacent surface water of similar density, colder bottom water is forced upwards in its place (Glenn et al. 1996, 2004). Cessation of wind can result in relaxation, where the denser bottom water sinks again and rapidly pulls displaced surface water back into the area. If the entrained bottom water is rich in organic material, biological demand during its isolation below the thermocline may deplete its oxygen. Dissolved oxygen remained mostly above the critical level $\left(<3 \mathrm{mg} \mathrm{ml}^{-1}\right)$ to which fishes commonly react (Coutant 1985, Craig \& Crowder 2005). Lower temperatures also coincided with higher salinity, making decomposition of their effects impossible. Thus, a relative statistical weakness of salinity as an explanatory variable in describing BSPL using forward selection should not be inter- 
preted as a lack of response. A longer time series might capture periods when these gradients become orthogonal, and the relationship of salinity with sound production could be examined in the field.

The full regression model including temperature, salinity, and dissolved oxygen only predicted about $41 \%$ of the variability in BSPL. Simple inspection of the time series suggests that the temperature response changes seasonally. Temperatures tend to be cold at the seasonal onset of spawning, resulting in high variability at low temperatures in a simple model (like Fig. 3) comparing temperature to sound pressure level. A time series model that incorporates seasonal change in variability necessitates the collection of multi-year datasets to inform it. This is precisely what an ocean observatory, like LEO-15, is designed to accomplish.
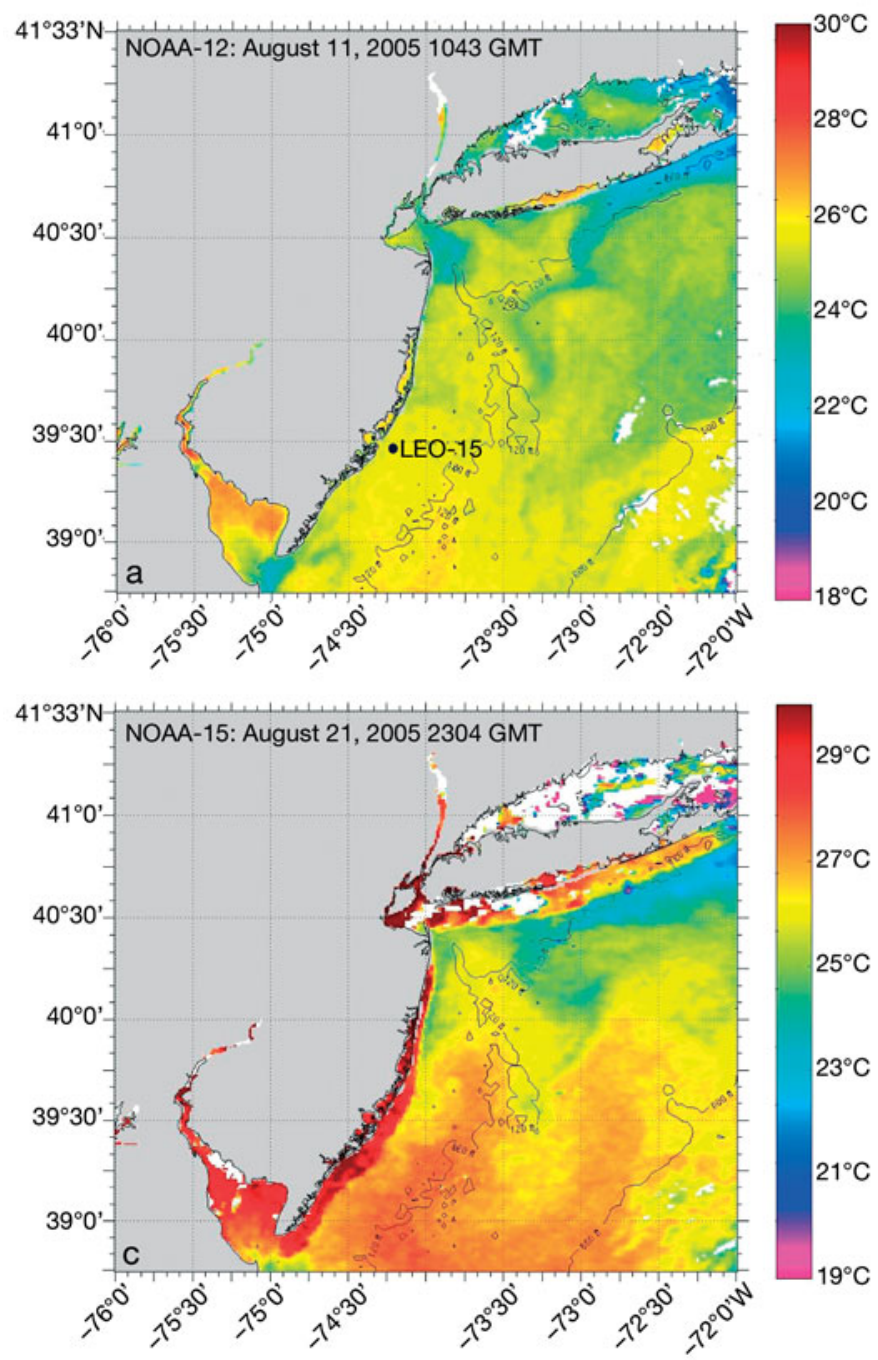

The level of detail provided by passive acoustic recordings of fish sound production can be used in coupled physical-biological models of spawning and egg transport for species in which the timing of sound

Table 1. Multiple regression with stepwise forward selection of variable (temperature, Temp; salinity, Sal; dissolved oxygen, DO) against nightly maximum sound pressure level at 200 to $300 \mathrm{~Hz}$. p: probability that the test statistic is greater than $F$ and is significant at 0.05 (bold). $\mathrm{N}=74$ nights

\begin{tabular}{|lccrrr|}
\hline $\begin{array}{c}\text { Step } \\
\text { Vadiables } \\
\text { added }\end{array}$ & $\begin{array}{c}\text { Partial } \\
\mathrm{R}^{2}\end{array}$ & $\begin{array}{c}\text { Model } \\
\mathrm{R}^{2}\end{array}$ & $F$ & $\mathrm{p}>F$ \\
\hline 1 & Temp & 0.3419 & 0.3419 & 37.41 & $\mathbf{< \mathbf { 0 0 0 0 1 }}$ \\
2 & Sal & 0.0373 & 0.3792 & 4.27 & $\mathbf{0 . 0 4 2 5}$ \\
3 & DO & 0.0267 & 0.4059 & 3.15 & 0.0804 \\
\hline
\end{tabular}
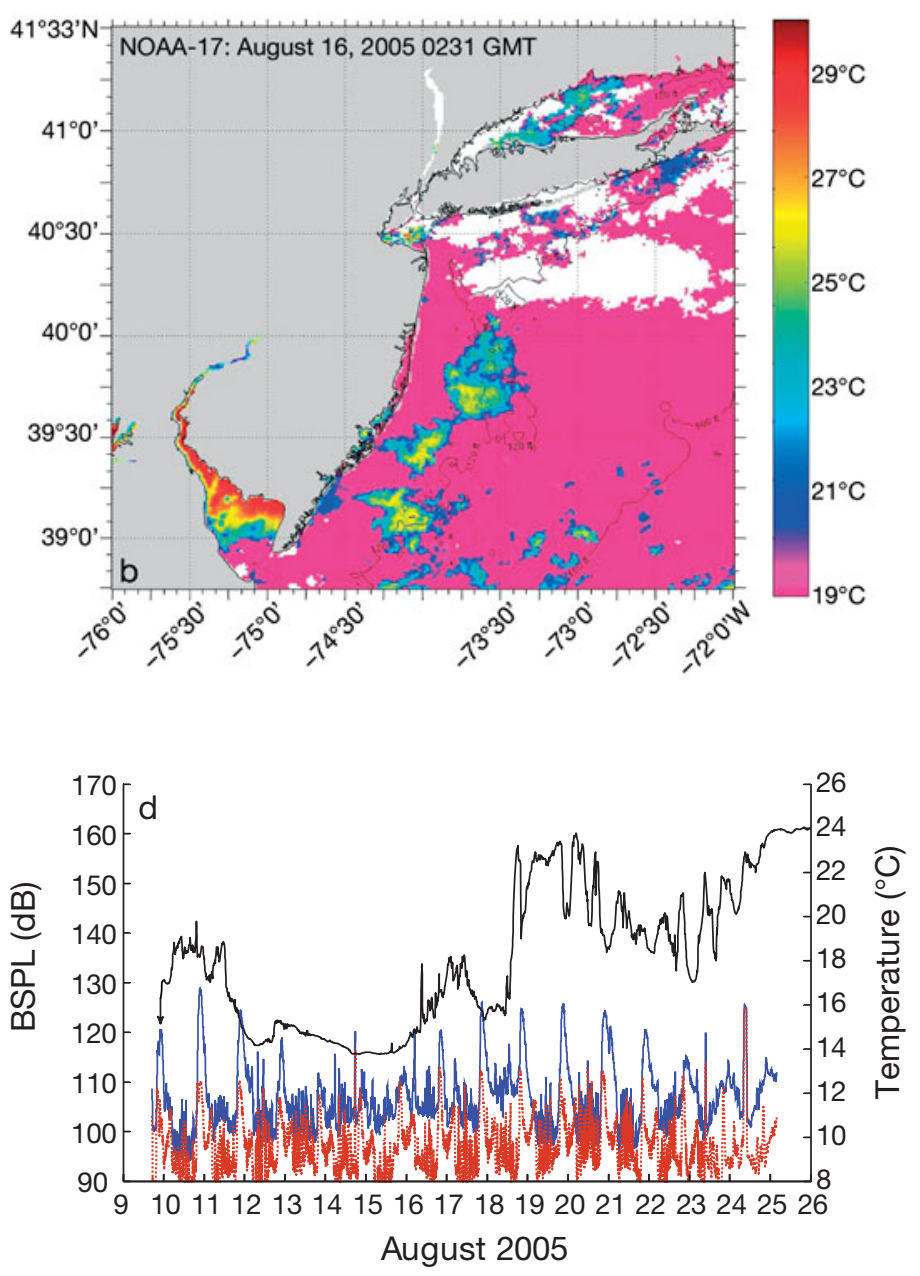

Fig. 3. (a to c) Sea-surface temperature satellite images of the LEO-15 area for August 11, 16, and 21, 2005. Note that color is scaled to the minimum and maximum temperatures. (d) Ophidion arginatum, Cynoscion regalis, Micropogonias undulatus. Time series of water temperature (black) at LEO-15, and sciaenid band sound pressure levels (blue; BSPL: 200 to $300 \mathrm{~Hz}$ ) and cusk-eel sound levels (dotted red; BSPL 800 to $1200 \mathrm{~Hz}$ ). The sound level plot was smoothed with an 11-point moving average to reduce noise spikes from boat traffic. Date tick marks are at midnight. Arrow: peak in sciaenid sound production on one day 

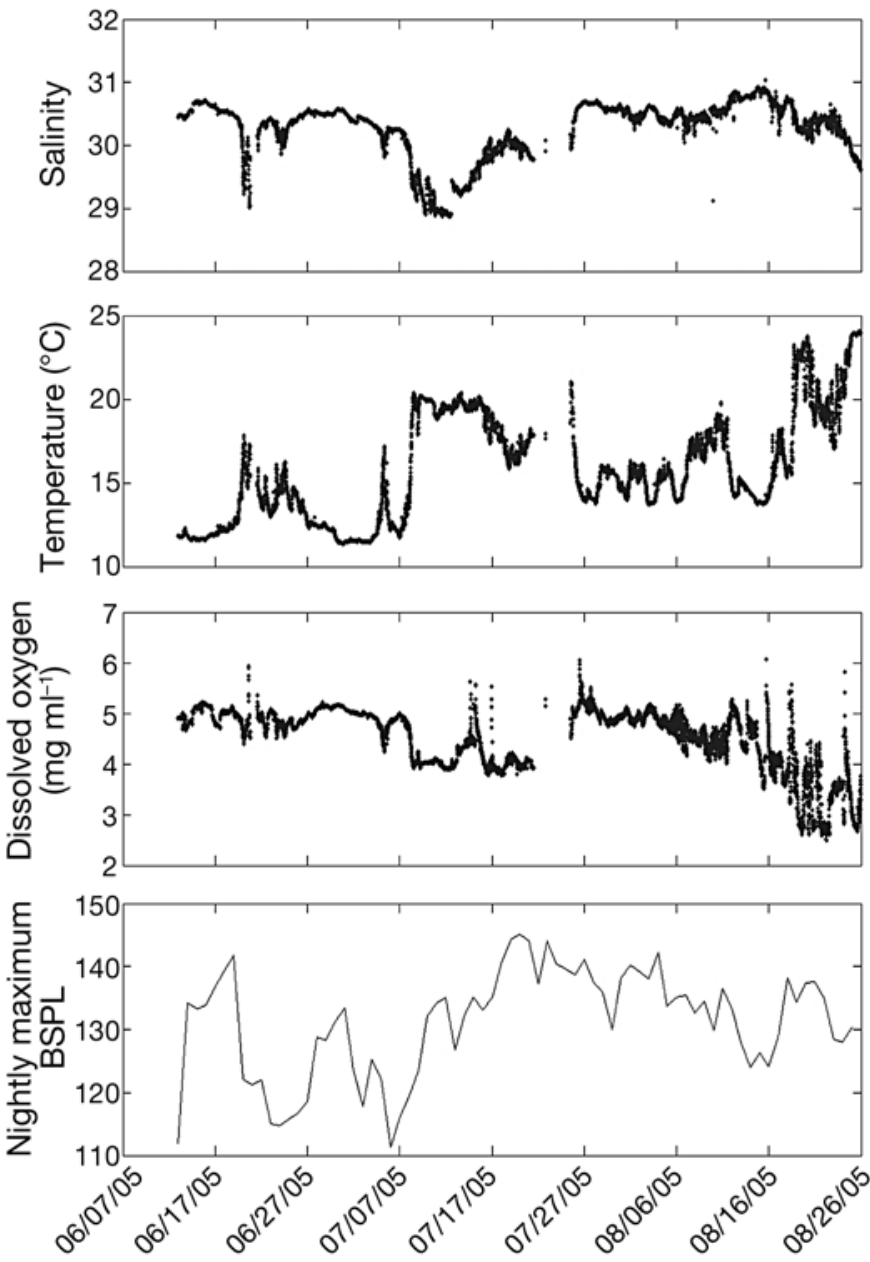

Fig. 4. Cynoscion regalis, Micropogonias undulatus. Variation in salinity, temperature, and dissolved oxygen of bottom water ( $>12 \mathrm{~m}$ depth) during sound production by sciaenids, showing alternation between periods of cold, high-salinity water, often with higher oxygen content (indicative of deeper water forced onto the sand ridge during wind-induced upwelling) and warmer, less-saline water from the mixed layer

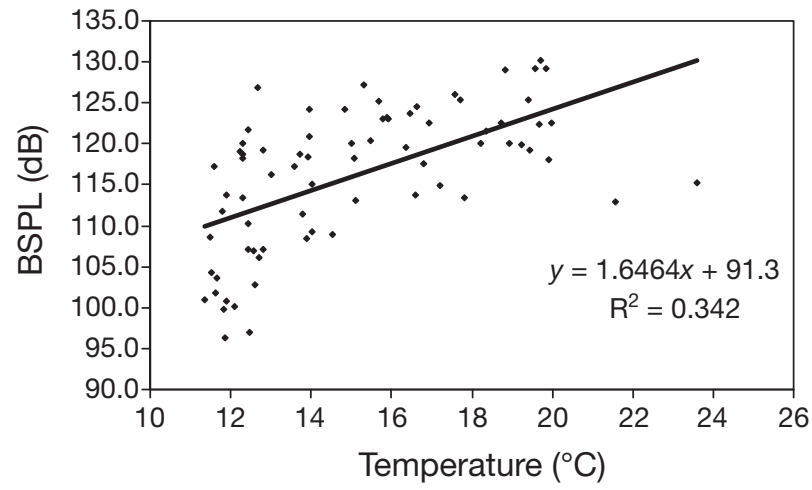

Fig. 5. Cynoscion regalis, Micropogonias undulatus. Regression of temperature at time of the maximum sound production each night versus maximum BSPL (average band sound pressure level of sciaenid sounds between 200 and $300 \mathrm{~Hz}$ ). $\mathrm{N}=74$ nights production can be linked to the timing of spawning. Hydrophones are one of the most robust and inexpensive sensors that can be used on ocean observatories to monitor biological activity. The detail shown here in the rapid response of fish to cold water intrusion demonstrates that hydrophones should be incorporated on all future ocean observatories as a standard sensor, just as temperature and salinity are standard measurements.

Acknowledgements. We thank R. Petrecca, J. Dobarro, and Captain J. Zlotnick of the LEO-15 science dive program. J. Kohut and S. Glenn were instrumental in gathering and managing hydrographic data at the node and in making it accessible to us. We thank 2 anonymous reviewers and the editor J. Hare for extensive comments that improved this manuscript. This work was supported by a grant from the National Oceanographic and Atmospheric Administration/ National Undersea Research Program (NOAA/NURP). This is Institute of Marine and Coastal Sciences Contribution No. 2008-14 from Rutgers University.

\section{LITERATURE CITED}

Able KW, Hagan SM (1995) Fishes in the vicinity of Beach Haven Ridge: annual and seasonal patterns of abundance during the early 1970s. Inst Mar Coastal Sci Tech Rept 9524, Rutgers University, New Brunswick, NJ

Arnold CR, Lasswell JL, Bailey WH, Fable WA Jr, Williams TD (1976) Methods and techniques for spawning and rearing spotted seatrout (Cynoscion nebulosus). In: Proc Annu Conf Southeastern Assoc Game Fish Comm 30:167-178

Beardsley RC, Boicourt WC, Hansen DV (1976) Physical oceanography of the Middle Atlantic Bight. In: Gross MG (ed) Middle Atlantic continental shelf and the New York Bight. Am Soc Limnol Oceanogr Spec Symp 2:20-33

Breder CM Jr (1968) Seasonal and diurnal occurrences of fish sounds in a small Florida Bay. Bull Am Mus Nat Hist 138:278-329

Bryan JD, Kelsch SW, Neill WH (1990) The maximum power principle in behavioral thermoregulation by fishes. Trans Am Fish Soc 119:611-621

Bumpus DF (1973) A description of the circulation on the continental shelf of the east coast of the United States. Prog Oceanogr 6:111-157

Churchill JH, Cornillon PC (1991) Gulf Stream water on the shelf and upper slope north of Cape Hatteras. Cont Shelf Res 11:409-431

> Coutant CC (1985) Striped bass, temperature, and dissolved oxygen: a speculative hypothesis for environmental risk. Trans Am Fish Soc 114:31-61

Craig JK, Crowder LB (2005) Hypoxia-induced habitat shifts and energetic consequences in Atlantic croaker and brown shrimp on the Gulf of Mexico shelf. Mar Ecol Prog Ser 294:79-94

Fish MP, Mowbray WH (1970) Sounds of western North Atlantic fishes. A reference file of biological underwater sounds. The John Hopkins Press, Baltimore, MD

Flagg CN, Houghton RW, Pietrafesa LJ (1994) Summertime thermocline salinity maximum intrusions in the MidAtlantic Bight. Deep-Sea Res II Top Stud Oceanogr 41: $325-340$

Fry FEJ (ed) (1971) The effect of environmental factors on the physiology of fish, Vol VI. Academic Press, New York 
Glenn SM, Crowley MF, Haidvogel DB, Song YT (1996) Underwater observatory captures coastal upwelling events off New Jersey. Trans Am Geophys Union 77: 223-236

Glenn S, Arnone R, Bergmann T, Bissett WP and others (2004) Biogeochemical impact of summertime coastal upwelling on the New Jersey Shelf. J Geophys Res 109:C12S02

Grothues TM, Able KW (2003) Determining vegetation and environmental correlates with subtidal marsh fish assemblage dynamics during Phragmites eradication efforts: interannual trend measures. Estuaries 26:574-586

Hare JA, Able KW (2007) Mechanistic links between climate and fisheries along the east coast of the United States: explaining population outbursts of Atlantic croaker (Micropogonias undulatus). Fish Oceanogr 16:31-45

Locascio JV, Mann DA (2008) Diel periodicity of fish soundproduction in Charlotte Harbor, Florida. Trans Am Fish Soc 137:606-615

Luczkovich JJ, Sprague MW, Johnson SE, Pullinger RC (1999) Delimiting spawning areas of weakfish, Cynoscion regalis (family Sciaenidae), in Pamlico Sound, North Carolina using passive hydroacoustic surveys. Bioacoustics 10:143-160

Luczkovich J, Mann D, Rountree R (2008) Passive acoustics as a tool in fisheries science. Trans Am Fish Soc 137:533-541

Mann DA, Lobel PS (1995) Passive acoustic detection of sounds produced by the damselfish Dascyllus albisella (Pomacentridae). Bioacoustics 6:199-213

Mann DA, Bowers-Altman J, Rountree RA (1997) Sounds pro-

Editorial responsibility: Jon Hare,

Narragansett, Rhode Island, USA duced by the striped cusk eel, Ophidion marginatum, during courtship and spawning. Copeia 1997:610-612

Martino EJ, Able KW (2003) Fish assemblages across the marine to low salinity transition zone of a temperate estuary. Estuar Coast Shelf Sci 56:969-987

McKibben JR, Bass AH (1998) Behavioral assessment of acoustic parameters relevant to signal recognition and preference in a vocal fish. J Acoust Soc Am 104:3520-3533

Mok HK, Gilmore RG (1983) Analysis of sound production in estuarine spawning aggregations of Pogonias cromis, Bairdiella chrysura, and Cynoscion nebulosus (Sciaenidae). Bull Acad Zool Acad Sinica 22:157-186

Musick JA, Colvocoresses JA, Foell EJ (1989) Seasonality and the distribution, availability and composition of fish assemblages in the Chesapeake Bight. Proc Siuec, Rio Grande, p 337-376

Saucier MH, Baltz DM (1993) Spawning site selection by spotted seatrout, Cynoscion nebulosus, and black drum, Pogonias cromis, in Louisiana. Environ Biol Fishes 36:257-272

Vasslides JM, Able KW (2008) Importance of shoreface sand ridges as habitat for fishes of the northeast coast of the USA. Fish Bull (Wash DC) 106:93-107

von Alt CJ, Grassle JF (1994) LEO-15: an unmanned long term environmental observatory. Proc Oceans 92, Newport, RI, p 849-854

Zelick R, Mann DA, Popper AN (1999) Acoustic communication in fishes and frogs. In: Fay RR, Popper AN (eds) Comparative hearing: fish and amphibians. Springer, New York, p 363-411

Submitted: January 21, 2008; Accepted: August 29, 2008 Proofs received from author(s): December 16, 2008 